\title{
Shear Behavior and Performance of Deep Beams Made with Self-Compacting Concrete
}

\author{
Y. W. Choi ${ }^{2)}$, H. K. Lee ${ }^{1), *}$, S. B. Chu $^{2)}$, S. H. Cheong ${ }^{3)}$, and W. Y. Jung ${ }^{4)}$ \\ (Received April 6, 2011, Revised February 13, 2012, Accepted February 13, 2012, Published online July 1, 2012)
}

\begin{abstract}
An experimental study was carried out to evaluate fresh properties of a moderately high-strength (high-flowing) selfcompacting concrete (SCC) and to investigate shear behavior and performance of deep beams made with SCC. Fresh and hardened properties of normal concrete (NC) and SCC were evaluated. The workability and compacting ability were observed based on casting time and number of surface cavities, respectively. Four-point loading tests on four deep beams (two made with SCC and two with $\mathrm{NC}$ ) were then conducted to investigate their shear behavior and performance. Shear behavior and performance of beams having two different web reinforcements in shear were systematically investigated in terms of crack pattern, failure mode, and load-deflection response. It was found from the tests that the SCC specimen having a normal shear reinforcement condition exhibited a slightly higher load carrying capacity than the corresponding NC specimen, while the SCC specimen having congested shear reinforcement condition showed a similar load carrying capacity to the corresponding NC specimen. In addition, a comparative study between the present experimental results and theoretical results in accordance with ACI 318 (Building Code Requirements for Reinforced Concrete (ACI 318-89) and Commentary-ACI 318R-89, 1999), Hsu-Mau's explicit method (Hsu, Cem Concr Compos 20:419-435, 1998; Mau and Hsu, Struct J Am Concr Inst 86:516-523, 1989) and strut-and-tie model suggested by Uribe and Alcocer (2002) based on ACI 318 Appendix A (2008) was carried out to assess the applicability of the aforementioned methods to predict the shear strength of SCC specimens.
\end{abstract}

Keywords: self-compacting concrete, fresh and hardened properties, workability, compacting ability, shear behavior and performance, deep beam, design approach.

\section{List of symbols}

$A_{v} \quad$ Vertical web reinforcement

$A_{v h} \quad$ Horizontal web reinforcement

$V_{n} \quad$ Nominal shear strength of a RC section

$V_{c} \quad$ Shear strength of the concrete

$V_{s} \quad$ Shear strength of reinforcement steel

$V_{u} \quad$ Factored shear force at critical section

$M_{u} \quad$ Factored moment at critical section

ald Shear span to effective depth ratio

$b_{w} \quad$ Web width of the beam

d Effective depth

$d_{v} \quad$ Distance between the centroid of the top and bottom stringers

\footnotetext{
${ }^{1)}$ Department of Civil and Environmental Engineering, KAIST, Daejeon 305-701, South Korea.

*Corresponding Author; E-mail: leeh@kaist.ac.kr

${ }^{2)}$ Department of Civil Engineering, Semyung University, Jecheon, Chungbuk 390-711, South Korea.

${ }^{3)}$ POSCO E \& C Co., Yeonsu-Gu, Incheon 406-840, South Korea.

${ }^{4}$ H.B. Technology, Yongtan-Dong, Chunju-Si 620-22, South Korea.
}

Copyright ( $\odot$ The Author(s) 2012. This article is published with open access at Springerlink.com $h \quad$ Total depth of the beam

$l_{n} / d \quad$ Effective span-to-depth ratio

s Second

$s_{v} \quad$ Spacing of the vertical web reinforcement

$s_{h} \quad$ Spacing of the horizontal web reinforcement

$v_{u} \quad$ Ultimate shear stresses of a RC section

$f_{l y} \quad$ Average steel stresses in the horizontal direction

$f t_{y} \quad$ Average steel stresses in the vertical direction

$f_{c} \quad$ Compressive strength of concrete

$\rho_{w} \quad$ Longitudinal reinforcement ratio

$f_{s y} \quad$ Yield strength of the web reinforcement

$\rho_{l} \quad$ Steel reinforcement ratio in the horizontal direction

$\rho_{t} \quad$ Steel reinforcement ratio in the vertical direction

$\omega_{l} \quad$ Reinforcement index in the longitudinal (horizontal) direction

$\omega_{t} \quad$ Reinforcement index in the transverse (vertical) direction

C Cement

G Coarse aggregates

FA Fly ash

$K \quad$ Function of the shear span ratio

LVDT Linear variable differential transducers

NC Normal concrete

PF Packing factor

$\mathrm{S} \quad$ Fine aggregates

SCC Self-compacting concrete 


$\begin{array}{ll}\text { S.F. } & \text { Shear-compression failure } \\ \text { SG } & \text { Blast furnace slag } \\ \text { SP } & \text { Superplasticizer } \\ \text { W } & \text { Water } \\ \varnothing & \text { Diameter of cavity }(\mathrm{mm})\end{array}$

\section{Introduction}

Overcrowded arrangement of rebars in reinforced concrete (RC) members, such as columns and beams, makes it difficult to compact concrete properly with the use of a mechanical vibrator. Unfilled voids and macro-pores inside concrete stemming from improper vibration and compaction may affect the mechanical strength and durability of the concrete and are among potential causes of deterioration in concrete (Broomfield 2003). Self-compacting concrete (SCC), first developed by Okamura in 1986 (Okamura et al. 1998; Okamura 1999), is considered a promising solution to solve the above mentioned problems. Since its introduction, the potential of SCC for construction of buildings and civil works has been explored in many countries including Japan, Canada, the USA, and some European countries (Domone 2006). The key advantage of SCC over normal concrete (NC) is its ability to fill all spaces in the formwork by its own weight. There is no need for vibration or for skilled workers to operate vibration machines, and therefore this reduces project costs. Although widespread application of SCC is still hindered by a lack of manuals and codes, it is expected that SCC will gain more popularity globally as a cost saving option.

There have been a number of notable studies on structural shear behavior and performance of RC structures made with SCC (Choulli et al. 2008; Hassan et al. 2008, 2010; Lachemi et al. 2005). Lachemi et al. (2005) carried out a series of experimental tests to investigate the shear resistance of SCC and $\mathrm{NC}$ on eighteen RC beams without reinforcements in shear. The key variables included concrete type, maximum size of coarse aggregate, coarse aggregate content, and shear span-to-depth ratio of specimen (Lachemi et al. 2005). Crack patterns and failure modes of all tested beams were observed with SCC and NC beams (Lachemi et al. 2005). Shear strength and ductility were evaluated and shear resistance mechanisms of SCC and NC beams were analyzed in both pre- and post-cracking stages (Lachemi et al. 2005). An experimental and theoretical study was carried out by Choulli et al. (2008) to determine safety and effectiveness of SCC for use in precast pre-stressed beams. Variables used in their study were the concrete type, the existence of shear reinforcement, the amount of horizontal web reinforcement, and the prestressing level (Choulli et al. 2008). The experimental results showed a roughly $10 \%$ decrease in shear capacity for beams made with SCC in comparison with those made with NC with the same compressive strength (Choulli et al. 2008). The study also reported that SCC provides more ductility for structural members than NC (Choulli et al. 2008). In addition, theoretical results for all codes were found to be conservative compared to all specimens in ultimate shear load capacities (Choulli et al. 2008). Hassan et al. (2008) experimentally compared the shear strength and cracking behavior of full-scale reinforced beams made with SCC and NC. The variables used in their study were concrete type, coarse aggregate content, beam depth, and the longitudinal reinforcing steel ratio (Hassan et al. 2008). The behavior and performance of beams made with SCC and NC were investigated in terms of crack pattern, crack widths, loads at the first flexure and diagonal cracking, ultimate shear resistance, and failure modes (Hassan et al. 2008). From their work, the ultimate shear strength of SCC beams was found to be slightly lower than that of $\mathrm{NC}$ beams; however, the difference was more pronounced with a reduction of the longitudinal reinforcing steel ratio and with an increase of beam depth (Hassan et al. 2008). A comparative study was conducted using design codes to assess the applicability of equations in codes to predict the shear resistance of SCC and NC beams (Hassan et al. 2008). Twenty beams without shear reinforcement were tested by Hassan et al. (2010) to evaluate the shear strength, cracking behavior, and deflection characteristics of largescale concrete beams made with both SCC and NC under three-point loading. Key variables consisted of concrete type, coarse aggregate content, beam depth $(150-750 \mathrm{~mm})$, and longitudinal reinforcing steel ratio (1 and $2 \%$ ) (Hassan et al. 2010). It was seen from the results that the ultimate shear strength of beams made with SCC was slightly lower than that of beams made with NC (Hassan et al. 2010).

Up to date, a number of research on shear behavior and performance of slender RC structures made with SCC (Choulli et al. 2008; Hassan et al. 2008, 2010; Lachemi et al. 2005). However, there are limited number of experimental and theoretical studies on shear behavior and the performance of deep beams made with SCC (Londhe 2011; Shah and Modhera 2010). Unlike slender RC structures, the shear capacity of deep beams was transferred by the tied arch behavior or action (Omeman et al. 2008). Thus, more systematical experiments and theoretical approaches on shear behavior and performance of the deep beam made with SCC should be made. In the present study, a series of experimental tests were carried out to evaluate fresh properties (e.g., flowability, segregation resistance and self compacting ability) of a moderately high-strength (high-flowing) SCC and to investigate the shear behavior and performance of deep beams made with SCC in our preceding work (Choi et al. 2006). Fresh properties of the SCC were evaluated based on the slump flow and V-funnel and U-box tests, and hardened properties of the $\mathrm{NC}$ and SCC were measured from compressive strength tests. The workability and compacting ability was observed by measuring casting time and number of surface cavities of specimens with two different types of web reinforcement in shear, respectively. Four-point loading tests were carried out to compare the shear behavior and performance of deep beams made with the SCC with those of deep beams made with NC. Shear behavior and performance of the deep beams made with NC and SCC were systematically investigated in terms of crack pattern, failure mode, and load-deflection response. In addition, a comparison between the present experimental results and theoretical results by using ACI 318 (1999), Hsu-Mau's explicit method (Hsu 1998; Mau and Hsu 1989) and Uribe and 
Table 1 Physical/chemical characteristics of cement and admixtures (cf. Table 1 of Choi et al. 2008).

\begin{tabular}{|c|c|c|c|c|c|c|c|c|c|c|c|}
\hline & $\begin{array}{c}\mathrm{SiO}_{2} \\
(\%)\end{array}$ & $\begin{array}{c}\mathrm{Al}_{2} \mathrm{O}_{3} \\
(\%)\end{array}$ & $\begin{array}{c}\mathrm{Fe}_{2} \mathrm{O}_{3} \\
(\%)\end{array}$ & $\begin{array}{c}\mathrm{CaO} \\
(\%)\end{array}$ & $\begin{array}{c}\mathrm{Na}_{2} \mathrm{O} \\
(\%)\end{array}$ & $\begin{array}{c}\mathrm{K}_{2} \mathrm{O} \\
(\%)\end{array}$ & $\begin{array}{c}\mathrm{MgO} \\
(\%)\end{array}$ & $\begin{array}{l}\mathrm{SO}_{3} \\
(\%)\end{array}$ & LOI & $\begin{array}{c}\rho \\
\left(\mathrm{g} / \mathrm{cm}^{3}\right)\end{array}$ & $\begin{array}{c}\text { SSA } \\
\left(\mathrm{cm}^{2} / \mathrm{g}\right)\end{array}$ \\
\hline OPC & 21.60 & 6.00 & 3.10 & 61.40 & - & - & 3.40 & 2.50 & 0.03 & 3.15 & 3,539 \\
\hline SG & 33.33 & 15.34 & 0.44 & 42.12 & - & - & 5.70 & 2.08 & 3.00 & 2.90 & 4,159 \\
\hline FA & 58.20 & 26.28 & 7.43 & 6.51 & 0.80 & - & 1.10 & 0.30 & 3.20 & 2.18 & 3,550 \\
\hline
\end{tabular}

LOI loss on ignition, $\rho$ density, $S S A$ specific surface area, $O P C$ ordinary Portland cement, $S G$ blast furnace slag, $F A$ fly ash.

Table 2 Physical properties of aggregates (cf. Table 2 of Choi et al. 2008).

\begin{tabular}{c|c|c|c|c}
\hline Aggregates & $\begin{array}{c}\text { Maximum } \\
\text { size }(\mathrm{mm})\end{array}$ & $\begin{array}{c}\text { Density }(\mathrm{g} / \\
\left.\mathrm{cm}^{3}\right)\end{array}$ & $\begin{array}{c}\text { Absorption } \\
(\%)\end{array}$ & $\begin{array}{c}\text { Fineness } \\
\text { modulus }\end{array}$ \\
\hline \hline $\begin{array}{c}\text { Fine } \\
\text { aggregates }\end{array}$ & - & 2.57 & 2.07 & 2.76 \\
\hline $\begin{array}{c}\text { Coarse } \\
\text { aggregates }\end{array}$ & 20 & 2.67 & 1.01 & 6.94 \\
\hline
\end{tabular}

Alcocer's strut and tie model (2002) based on ACI 318 Appendix A (2008) was conducted to evaluate the applicability of the aforementioned methods for deep beams made with SCC.

\section{Experimental Program}

\subsection{Materials and Mix Design}

The materials used to cast the specimens in the present study consisted of Type I ordinary Portland cement, sands (fine aggregates), crushed stones (coarse aggregates) of $20 \mathrm{~mm}$ in maximum size, mineral admixtures (fly ash and blast furnace slag), and superplasticizer having polycarboxylic acid, which is used to improve the flowability of the SCC. The physical/chemical characteristics of the cement and the admixtures are listed in Table 1, and Table 2 summarizes the physical properties of the aggregates.

The mix design for the SCC followed that of our preceding works (Choi et al. 2002, 2003, 2006, 2008). The aggregate filling ratio for determining the $\mathrm{PF}$ value, which is defined as the ratio of mass of aggregate in a tightly packed state in SCC to that in a loosely packed state ( $\mathrm{Su}$ et al. 2001), and flowcharts of the mix design procedure for SCC are shown in Figs. 1 and 2 of Choi et al. (2006), respectively. Both NC and SCC specimens were designed for a moderately high-strength SCC of $50 \mathrm{MPa}$, and the mix proportions of the materials are given in Table 3. It should be noted that the cement and admixture characteristics, aggregate properties, and mix
Table 4 The material properties of steel.

\begin{tabular}{c|c|c|c}
\hline Type & $\begin{array}{c}\text { Yield strength } \\
(\mathrm{MPa})\end{array}$ & $\begin{array}{c}\text { Tensile strength } \\
\text { (MPa) }\end{array}$ & Elongation (\%) \\
\hline \hline Stirrups (D6) & 447 & 743 & 21 \\
\hline Rebars (D22) & 347 & 542 & 25 \\
\hline Rebars (D25) & 334 & 512 & 33 \\
\hline
\end{tabular}

Test data from Posco, Inc.

proportions for the SCC mixtures given in Tables 1, 2, and 3, respectively, are similar to those used in Choi et al. (2008) (see Tables 1, 2, and 6 therein). The yield strength, tensile strength, and elongation of the deformed steel rebars are given in Table 4.

\subsection{Material Properties of NC and HSCC \\ 2.2.1 Fresh Properties of NC and SCC}

Fresh properties of NC can be evaluated based on slump in accordance with ASTM C143 (2003), while those of SCC can be evaluated based on the slump flow and V-funnel and U-box tests in accordance with the JSCE (2005), as shown in Fig. 1. The evaluation was performed on the basis of the JSCE's 1st class criteria (2005) for flowing concrete, which represented the conditions for congested RC structures. The JSCE performance evaluation criteria for flowing concrete and test results are given in Table 5.

The slump test is the standard workability test for NC. The standard slump cone was filled with concrete and then the cone was lifted. With this apparatus, the slump-height of the $\mathrm{NC}$ was measured and the measured slump of the $\mathrm{NC}$ was $170 \mathrm{~mm}$ in accordance with ASTM C143 (2003), as shown in Fig. 1a. The slump flow test is more suitable for evaluating the flowability of a SCC. For SCC, the final diameter of the spread and the time for the slump to spread to $500 \mathrm{~mm}$ in diameter on a base plate were determined as shown in Fig. 1b. The measured slump flow of the SCC was $655 \mathrm{~mm}$, which satisfied the JSCE's 1st class criteria (2005) for flowability, as listed in Table 5. The time required to reach

Table 3 Mix proportion of concrete (cf. Table 6 of Choi et al. 2008).

\begin{tabular}{|c|c|c|c|c|c|c|c|c|c|}
\hline \multirow[t]{2}{*}{ Mix } & \multirow[t]{2}{*}{$\mathrm{PF}$} & \multirow[t]{2}{*}{ S/a (\%) } & \multicolumn{6}{|c|}{ Unit mass $\left(\mathrm{kg} / \mathrm{m}^{3}\right)$} & \multirow{2}{*}{$\mathrm{SP}(\mathrm{C} \times \%)$} \\
\hline & & & $\mathrm{W}$ & $\mathrm{C}$ & SG & $\mathrm{FA}$ & $\mathrm{S}$ & $\mathrm{G}$ & \\
\hline $\mathrm{NC}$ & - & 44 & 170 & 485 & 0 & 0 & 718 & 947 & 0.4 \\
\hline $\mathrm{SCC}$ & 1.12 & 48 & 175 & 351 & 46 & 70 & 769 & 864 & 0.6 \\
\hline
\end{tabular}

$P F$ packing factor, $S / a$ volume ratio of fine aggregates to total aggregates, $W$ water, $C$ cement, $S G$ blast furnace slag, $F A$ fly ash, $S$ fine aggregates, $G$ coarse aggregates, $S P$ superplasticizer. 


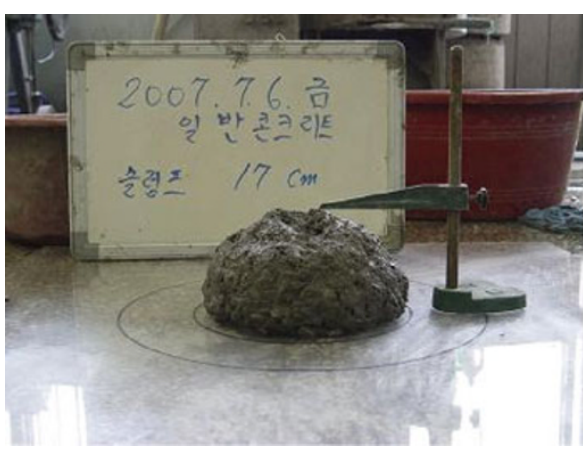

(a) Slump test for NC

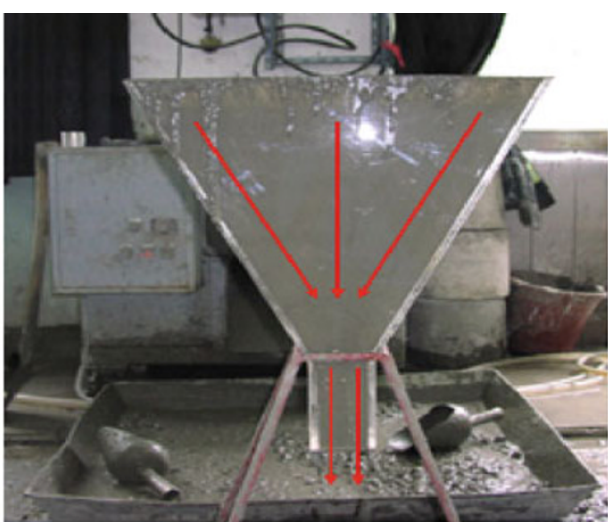

(c) V-funnel flow test for SCC

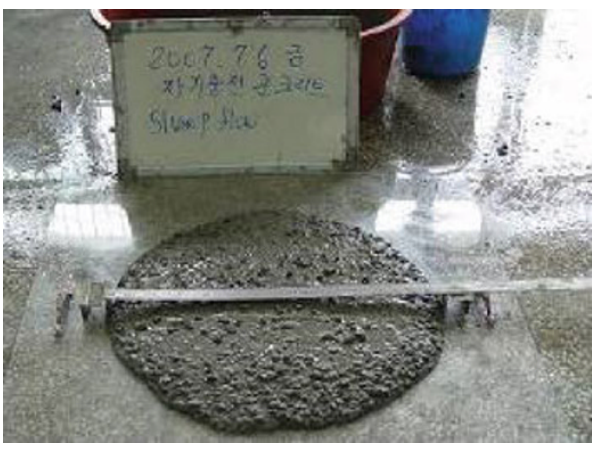

(b) Slump flow test for SCC

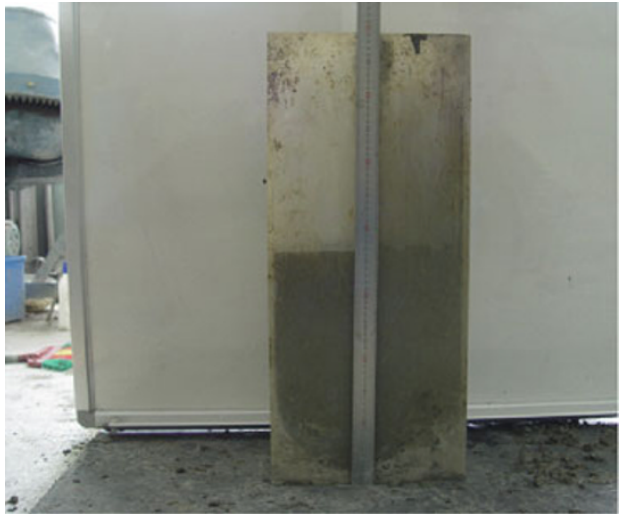

(d) U-box test for SCC

Fig. 1 Schematics of experimental tests for fresh properties of NC and SCC.

Table 5 JSCE performance evaluation criteria and test results for SCC.

\begin{tabular}{c|c|c|c}
\hline Item & Description & 1st class ${ }^{\text {a }}$ (JSCE) & Test results \\
\hline \hline Construction condition & Minimum gap between reinforcements (mm) & $30-60$ & - \\
\hline Flowability & Slump-flow (mm) & $600-700$ & 655 \\
\hline $\begin{array}{c}\text { Segregation resistance } \\
\text { ability }\end{array}$ & Time required to flow through V-funnel (s) & $9-20$ & 10.64 \\
\cline { 2 - 4 } & Time required to reach 500 mm of slump-flow (s) & $5-20$ & 6.61 \\
\hline Self compacting ability & Filling height of U-box (mm) & $\geq 300$ & $\geq 300$ \\
\hline
\end{tabular}

${ }^{a}$ Data taken from JSCE (2005).

$500 \mathrm{~mm}$ slump flow was measured to be $6.6 \mathrm{~s}$. This meets the JSCE's 1st class criteria (2005) for segregation resistance ability, as listed in Table 5. The V-shaped funnel, as shown in Fig. 1c, is used as one of the criteria for assessing the segregation resistance ability of SCC. In this test, the funnel was filled with SCC without rodding and then the bottom lid was opened. The time for the SCC to completely flow through the funnel was determined. The measured V-funnel time of $10.64 \mathrm{~s}$ is within the range for the JSCE's 1st class criteria (2005) and the results are listed in Table 5. The U-box test, illustrated in Fig. 1d, is used to evaluate the selfcompacting ability of SCC through an obstacle. SCC was filled in one section of the box and then the partition was pulled to allow the SCC to flow through the gaps between reinforcements (13 $\mathrm{mm}$ diameter) into the other section of the box. Fresh SCC with a filling height of over $300 \mathrm{~mm}$ can be judged as self-compacting in accordance with the 1 st class criteria of JSCE (2005). The filling height of SCC in the U-box test was above $300 \mathrm{~mm}$. This satisfies the JSCE's 1 st class criteria (2005) for self compacting ability, as listed in Table 5.

\subsubsection{Hardened Properties of NC and SCC}

Three cylindrical specimens using both NC and SCC mixtures having a dimension of $100 \mathrm{~mm}$ diameter and $200 \mathrm{~mm}$ height were prepared. Both the NC and SCC specimens were prepared in accordance with ASTM C192 (2007). However, it should be noted that the SCC specimens were cast without vibration. Molds were removed after $24 \mathrm{~h}$ followed by curing process in a water tank. The compressive strengths of NC and SCC were measured in accordance with ASTM C39 (2005) on cylindrical specimens after 28 days of curing. The results from the compressive strength tests on the NC and SCC specimens are summarized in Table 6. 
Table 6 Measured compressive strength of NC and SCC.

\begin{tabular}{c|c|c}
\hline Concrete type & $\begin{array}{c}\text { Specified concrete } \\
\text { strength (MPa) }\end{array}$ & $\begin{array}{c}\text { Compressive } \\
\text { strength (MPa) }\end{array}$ \\
\hline \hline $\mathrm{NC}$ & 50 & 55.2 \\
\hline $\mathrm{SCC}$ & 50 & 52.1 \\
\hline
\end{tabular}

\subsection{Specimens Preparation}

A total of four deep beams (two made with SCC and two with NC) were manufactured, where the size of the beams was $180 \mathrm{~mm}$ (width) $\times 360 \mathrm{~mm}$ (height) $\times 1,700 \mathrm{~mm}$ (length). Shear span to effective depth ratio $(a / d)$ was 1.43 for all deep beams so that shear compression or tension failure can be induced. Two deformed steel rebars with 22-mm diameter (D22) were placed at the top of deep beams, while four deformed steel rebars with $25-\mathrm{mm}$ diameter (D25) were situated at the bottom of the deep beams as longitudinal reinforcements. Web reinforcements, consisting of vertical closed stirrups with 6-mm diameter (D6), were incorporated in the deep beams. The NC specimens were cast as reference beams. NC-50 and SCC-50 specimens having stirrups spaced at $50 \mathrm{~mm}$ were manufactured as deep beams with congested reinforcement in shear, as shown in Fig. 2a, while NC-100 and SCC-100 specimens having stirrups spaced at $100 \mathrm{~mm}$ were casted as deep beams with a normal shear reinforcement condition, as shown in Fig. 2b. The formworks were detached after 7 days of casting. The specimens were covered with cloth and water was supplied to the specimens during the curing period for up to 28 days to prevent drying shrinkage cracks.

\subsection{Experimental Setup}

After removal of the formwork at the age of 7 days, the surface finish was inspected and the deep beams were subjected to a four-point loading to evaluate their shear behavior and performances. The setup for the four-point loading tests is shown in Fig. 3. Six linear variable differential transducers (LVDTs) were used to measure the vertical deflection of the specimens. Two among six LVDTs were located at the mid-span, one on each side of the beam, and four others were located at the supports to measure the support settlement. The four-point loading tests were carried out using a 3,000 kN capacity Universal Testing Machine (UTM) under displacement control at a constant headloading rate of $0.015 \mathrm{~mm} / \mathrm{s}$. Loads and vertical deflections were automatically recorded every $3 \mathrm{~s}$ using a SYSTEM 5000 data logger connected to a desktop computer until the specimens reached failure.

\section{Experimental Results}

\subsection{Workability and Compacting Ability}

In order to comparatively evaluate the workability of $\mathrm{NC}$ and SCC, casting times in the case of NC and SCC specimens were measured during casting of specimens. After formworks were detached, surface finish conditions were observed in order to evaluate the compacting ability of the NC and SCC specimens.

\subsubsection{Casting Time}

$\mathrm{NC}-50$ and $\mathrm{NC}-100$ specimen were cast into two layers at four different positions from sections A-D of the specimen as shown in Fig. 4a. After casting the first layer of $\mathrm{NC}$ for $\mathrm{NC}$ specimens, the vibration work was carried out with interval space of 50-70 $\mathrm{mm}$ along the longitudinal direction and the vibration time at each interval space was $20-25 \mathrm{~s}$ as shown in Fig. 5. Similar to the casting and the vibration method for the first layer of $\mathrm{NC}$, the second layer of $\mathrm{NC}$ for $\mathrm{NC}$ specimens

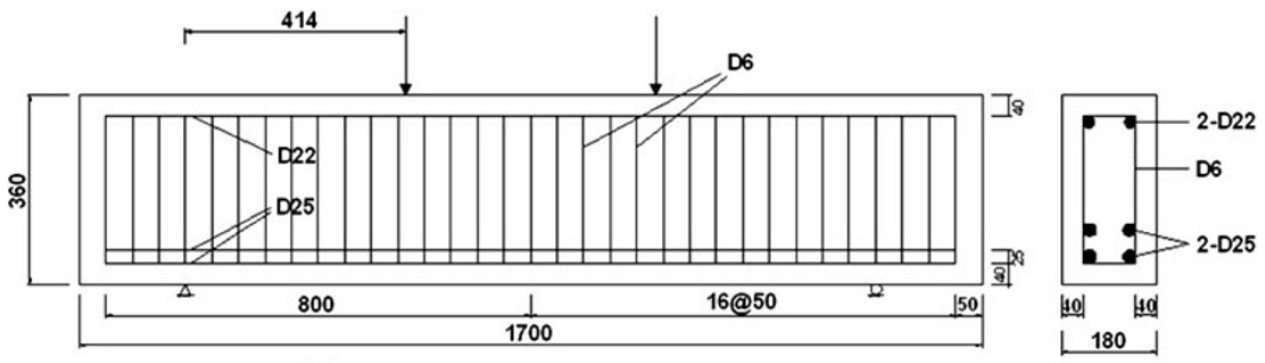

(a) NC-50 and SCC-50 specimens

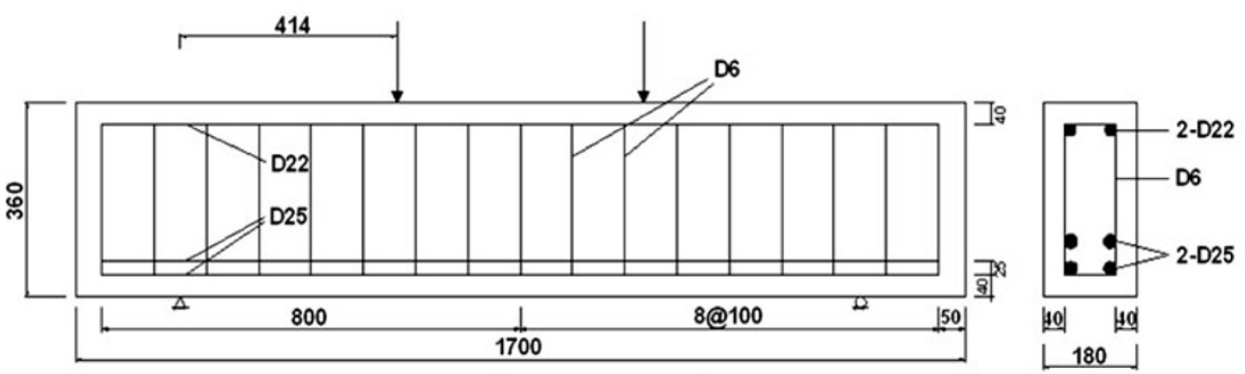

(b) NC-100 and SCC-100 specimens

Fig. 2 Details and dimensions of deep beams (dimensions in $\mathrm{mm}$ ). 


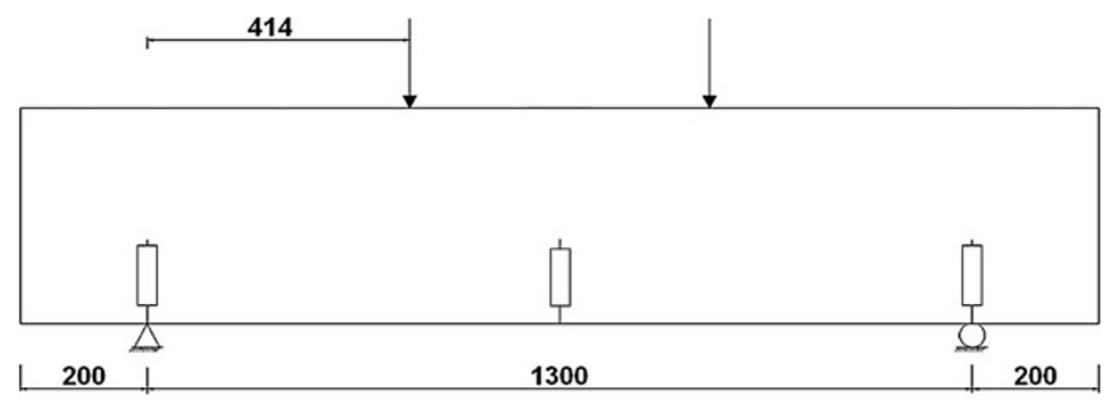

LVDT

(Dimensions in $\mathrm{mm}$ )

Fig. 3 Four-point loading test setup and position of the LVDTs.

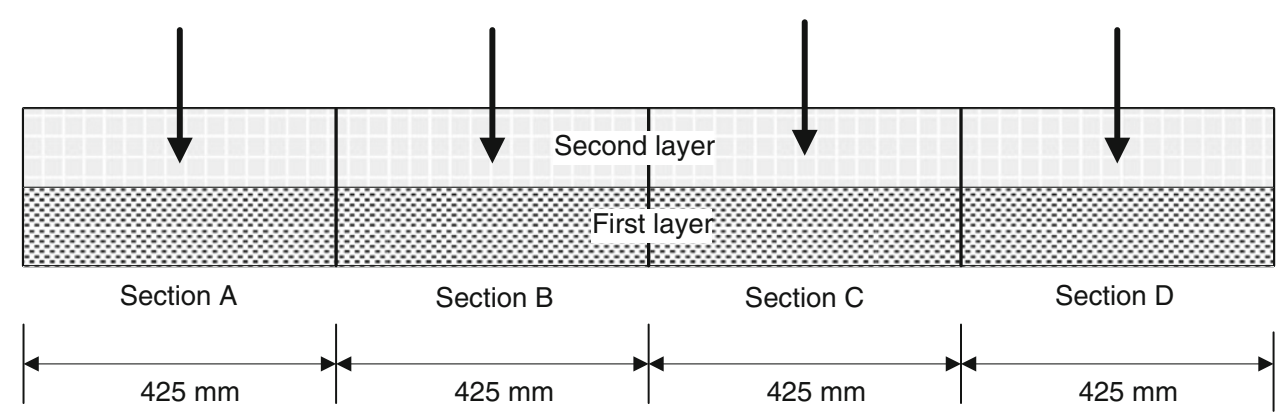

(a) casting positions for $\mathrm{NC}$

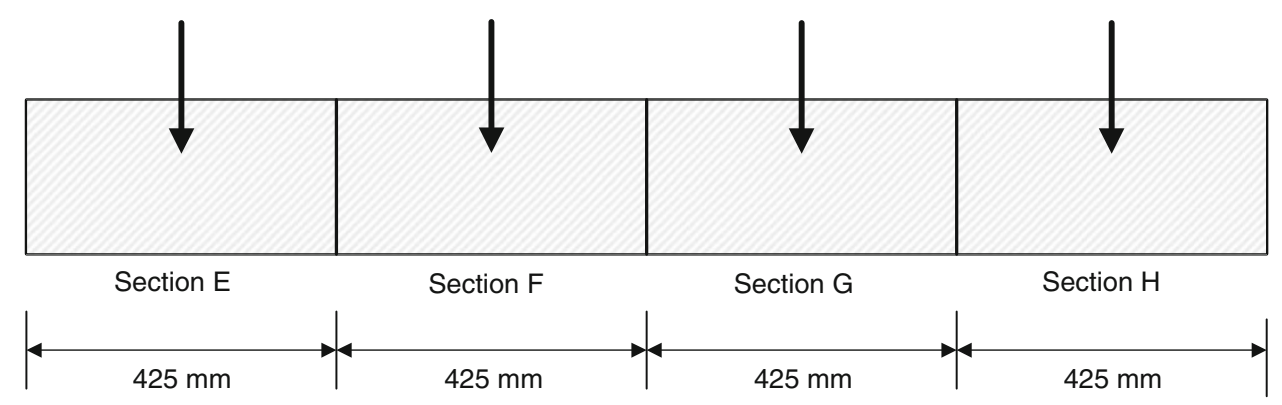

(b) casting positions for SCC

Fig. 4 Casting positions for NC and SCC specimens.

was cast at four different positions and then the vibration work was also conducted. Due to the congested shear reinforcement condition, the vibration work was carried out with great care during the casting of the NC specimens.

However, SCC-50 and SCC-100 specimen were cast in only one layer at four different positions from section $\mathrm{E}$ through $G$ of the specimens, as shown in Fig. $4 b$. In particular, casting of SCC was carried out in a laboratory so that the workers poured self compacting concrete into the formwork at each section of the specimen. The self compacting concrete for SCC specimens flowed easily and filled the formwork without vibration as shown in Fig. 6. During the fabrication of the deep beam, casting time was measured to evaluate the workability of $\mathrm{NC}$ and SCC. The total casting time of the NC-100 and SCC-100 specimens was about 20 and $7 \mathrm{~min}$, respectively, while that of the NC-50 and SCC50 specimens was about 22 and $8 \mathrm{~min}$ as listed in Table 7. The casting time of the SCC specimens was significantly shorter than that of the NC-specimens in the case of both normal and congested shear reinforcement conditions. The SCC was smoothly compacted in all the corners of the formwork by its own weight in the deep beams with both normal and congested stirrups. The influence of the concrete type (the NC and SCC mixes) on the casting time was shown to be very significant.

\subsubsection{Surface Finish Evaluation}

The NC specimens after the formwork was detached, as shown in Fig. 7a, b, exhibited the presence of surface cavities. Figure 7a shows an image of the NC-50 specimen after removal of the formwork. Cavities were clearly observed on the surface of the NC-50 specimen. As for the distribution of cavity diameter of $\mathrm{NC}-50$ specimen, 36 cavities were found to have diameter of $10 \mathrm{~mm}$ or above, with the greatest among them being approximately $22 \mathrm{~mm}$, as listed in Table 7 . In detail, the number of cavities with various diameters (smaller than $10 \mathrm{~mm}$ ) for NC-50 specimen was summarized in Table 7. Figure $7 \mathrm{~b}$ shows images of the NC-100 specimen 


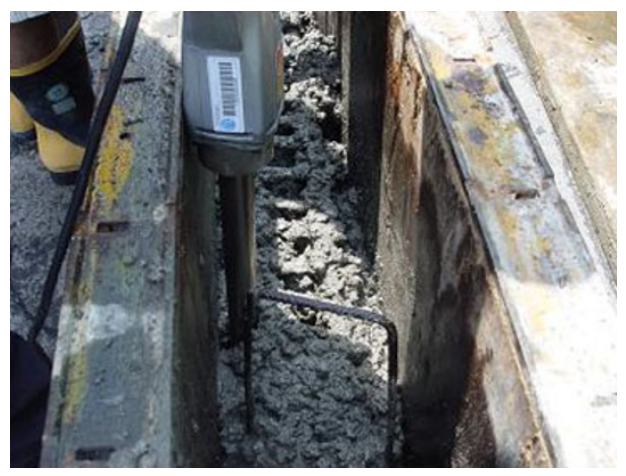

(a) NC-50 specimen

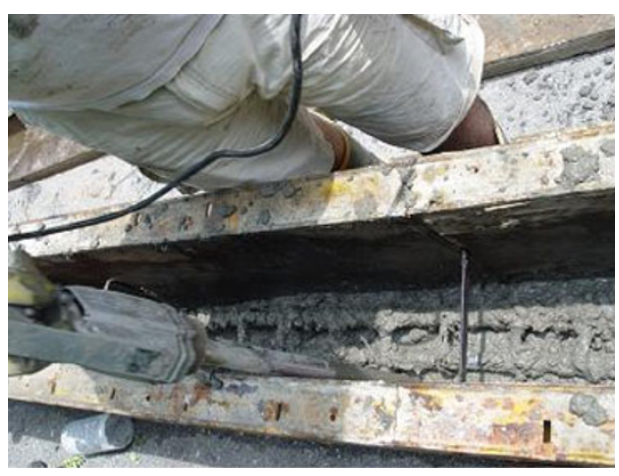

(b) NC-100 specimen

Fig. 5 The vibration work for NC specimens.

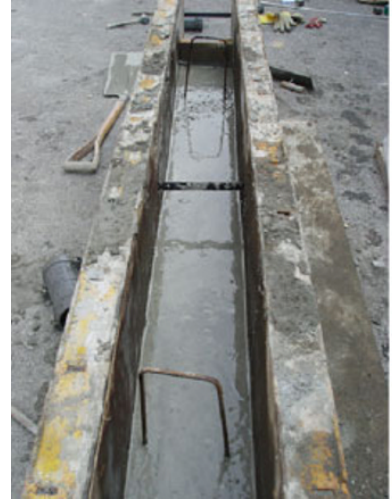

(a) SCC-50 specimen

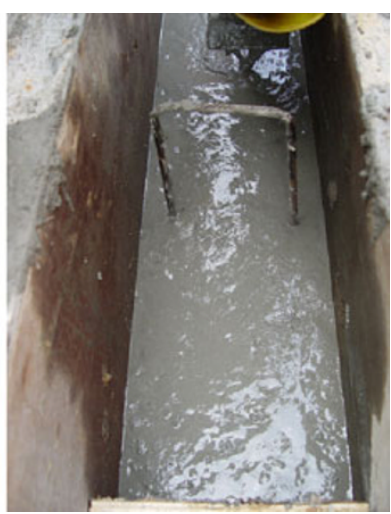

(b) SCC-100 specimen
Fig. 6 Self-compaction of SCC for SCC specimens.

after removal of the formwork. 18 cavities with diameter of $10 \mathrm{~mm}$ or above were counted. The number of easily recognizable cavities was lower than that in NC-50 specimen, where the maximum diameter was around $17 \mathrm{~mm}$, as listed in Table 7. In detail, the number of cavities with various diameters (smaller than $10 \mathrm{~mm}$ ) for NC-100 specimen was summarized in Table 7. Vibration work was performed but the compacting ability of NC specimens was poor. In particular, NC-50 specimen where reinforcements are placed densely showed poor filling characteristics and therefore the desired quality of the concrete surface cannot be ensured on a stable basis. Figure 7c, d show images of the SCC specimens, with a stirrup spacing of 50 and $100 \mathrm{~mm}$, respectively, after removal of the formwork. The maximum cavity diameter of both specimens was found to be approximately $13 \mathrm{~mm}$, as listed in Table 7. With regret, the authors missed measuring the cavity numbers with various diameters (smaller than $10 \mathrm{~mm}$ ) for SCC specimens so that there are no data in Table 7. Although they were not subjected to vibration work, the SCC specimens have small cavities, implying outstanding surface finishing characteristics. It was found that, regardless of the reinforcement intervals, SCC is capable of flowing by its own weight only and fills the gaps between reinforcements and all spaces in the formwork.

Based on the above results, the following conclusions can be drawn. SCC ensures the quality of concrete, as it demonstrates little difference according to the minimum reinforcement interval suggested by the JSCE's 1st class criteria and has outstanding surface finishing characteristics. NC, on the other hand, shows significant variation according to the spacing of stirrups, and consequently the filling characteristics of concrete are considerably poor at reinforcement intervals equivalent to the JSCE's 1 st class criteria, and as such it is difficult to stably ensure the quality of the concrete.

\subsection{Structural Behavior and Performance of Deep Beams}

For typical deep beams shear forces of deep beams were transferred to supports through compressive stresses rather

Table 7 Measured casting time and observed surface finishing.

\begin{tabular}{|c|c|c|c|c|}
\hline \multirow[t]{2}{*}{ Item } & \multicolumn{4}{|c|}{ Specimen } \\
\hline & NC-50 & $\mathrm{NC}-100$ & SCC-50 & SCC-100 \\
\hline Casting time (min.) & 22 & 20 & 8 & 7 \\
\hline $\begin{array}{l}\text { Maximum cavity } \\
\text { diameter }(\mathrm{mm})\end{array}$ & 22 & 17 & 13 & 13 \\
\hline \multicolumn{5}{|c|}{ No. of cavities at } \\
\hline$\emptyset^{*} \geq 10$ & 36 & 18 & 10 & 6 \\
\hline $7 \leq \emptyset^{*} \leq 9$ & 34 & 17 & $\mathrm{~N}$ & $\mathrm{~N}$ \\
\hline $4 \leq \emptyset^{*} \leq 6$ & 32 & 10 & $\mathrm{~N}$ & $\mathrm{~N}$ \\
\hline $1 \leq \emptyset^{*} \leq 3$ & 47 & 21 & $\mathrm{~N}$ & $\mathrm{~N}$ \\
\hline
\end{tabular}

$\varnothing^{*}$ diameter of cavity (mm), $N$ no measured data. 


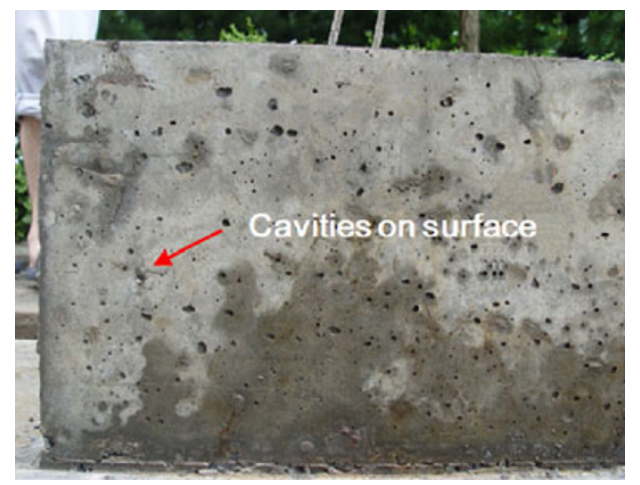

(a) NC-50 specimen

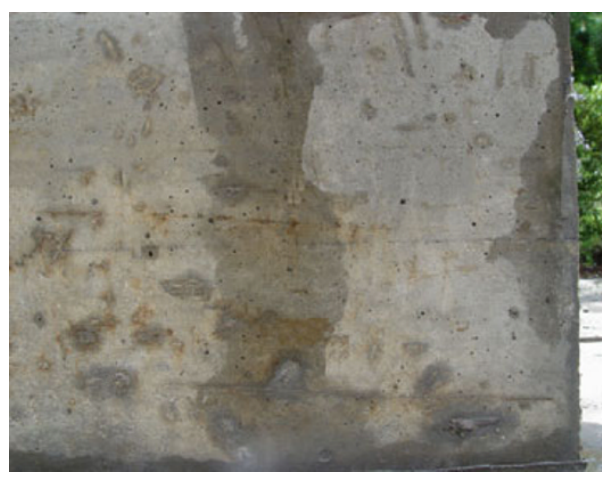

(c) SCC-50 specimen

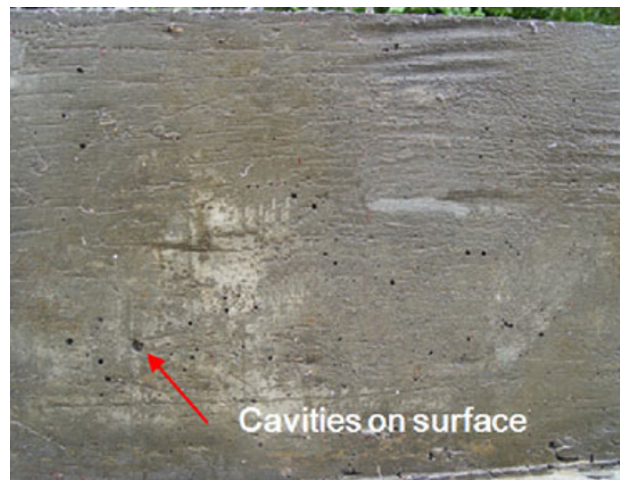

(b) NC-100 specimen

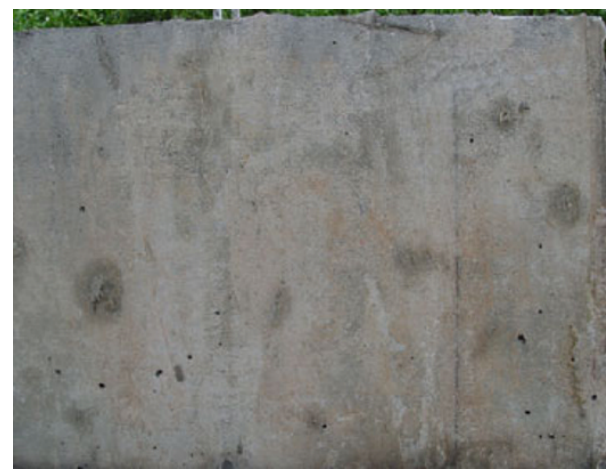

(d) SCC-100 specimen

Fig. 7 Surface finish evaluation of NC and SCC specimens.

than shear stresses (Omeman et al. 2008). Deep beam with $1.0<a / d<2.5$, which developed inclined cracks, are able to carry additional loads by an arch action after a redistribution of internal forces (MacGregor and Wight 2006). In this study, the tested RC beams are regarded as deep beams, since the shear span to effective depth ratio $(a / d)$ was 1.43 . Therefore, their shear behavior and performance can be illustrated by an arch action. Four-point loading tests were conducted on four deep beams: two different concrete types and vertical web reinforcements, respectively. The number of specimens used in the present study is not enough to suggest shear behavior of various types of deep beams. It should be, thus, noted that the present results are limited to the shear behavior and performance of deep beams with the compressive strength of about $55 \mathrm{MPa}$, the shear span to effective depth ratio $(a / d)$ of 1.43 and no horizontal distributed reinforcements in the web of the specimens.

\subsubsection{Crack Patterns and Failure Modes}

Figure 8 shows the crack pattern and failure mode of the tested deep beams. Sudden shear-compression failures were observed with all tested deep beams. As shown in Fig. 8a, the NC-50 specimen with congested web reinforcement exhibited typical shear-compression failure under the fourpoint loading. Flexural cracks appeared at the bottom side of the deep beam at a load of $128 \mathrm{kN}$. The flexural crack propagated vertically upward, but did not meet the inclined compression strut. As the applied load increased, diagonal shear cracks appeared through the inclined compression strut, especially at the center area of both shear spans, at a load of $314 \mathrm{kN}$. With increasing load, other shear cracks develop from one of the mid-spans to the lower area near the support and the deep beam reached sudden failure through the inclined compression strut at a load of $802 \mathrm{kN}$. The NC100 specimen with normal web reinforcements showed typical shear-compression failure under static load, as shown in Fig. $8 \mathrm{~b}$. The flexural cracks were initiated at the bottom of the deep beam at a load of $88 \mathrm{kN}$. However, flexural cracks stopped at a certain distance from the top of the deep beam and did not penetrate the compression zone. With increasing load, additional shear cracks appeared at both sides of the deep beam in layers parallel to the inclined compression strut at a load of $225 \mathrm{kN}$. Finally, the deep beam showed sudden brittle failure at a load of $676 \mathrm{kN}$.

Similar to the NC-50 specimen, the SCC-50 specimen, which has a congested web reinforcement, displayed typical shear compression failure, as shown in Fig. 8c. During the four-point loading test on the deep beam, flexural cracks initiated at the bottom side of the specimen at a load of $132 \mathrm{kN}$; however, flexural cracks stopped at a certain distance from the top of the deep beam and did not penetrate the compression zone. The diagonal shear cracks formed at both sides of the layers parallel to the inclined compression strut at a load of $324 \mathrm{kN}$. As the applied load was increased, diagonal shear cracks extended both downward to the support and upward to the applied load positions of specimens. Finally, sudden failure occurred at a load of $796 \mathrm{kN}$. The SCC-100 specimen, which has normal web reinforcement, represented typical shear-compression failure, as shown in Fig. 8d. Flexural cracks initiated at the bottom of the deep beam, due 


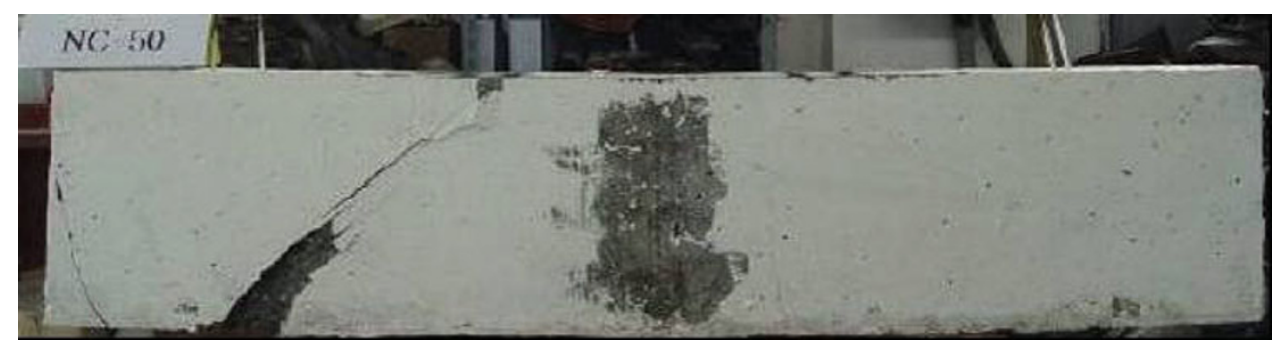

(a) NC-50 specimen

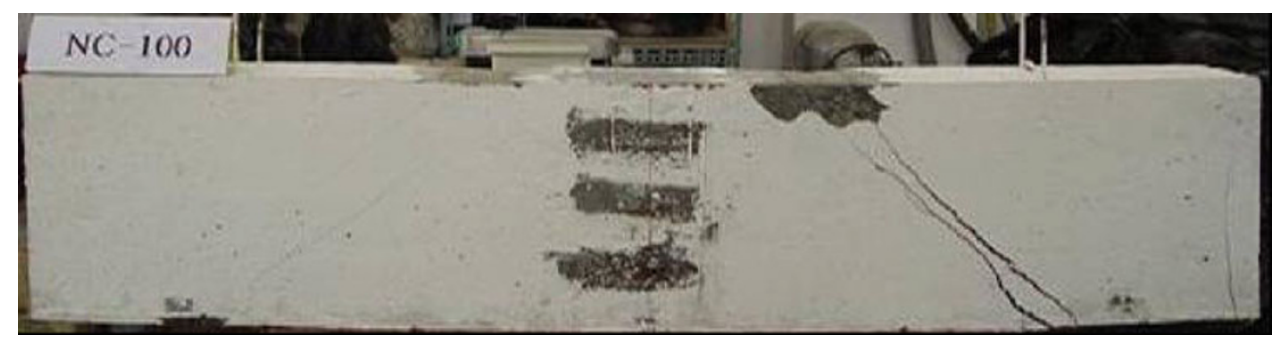

(b) NC-100 specimen

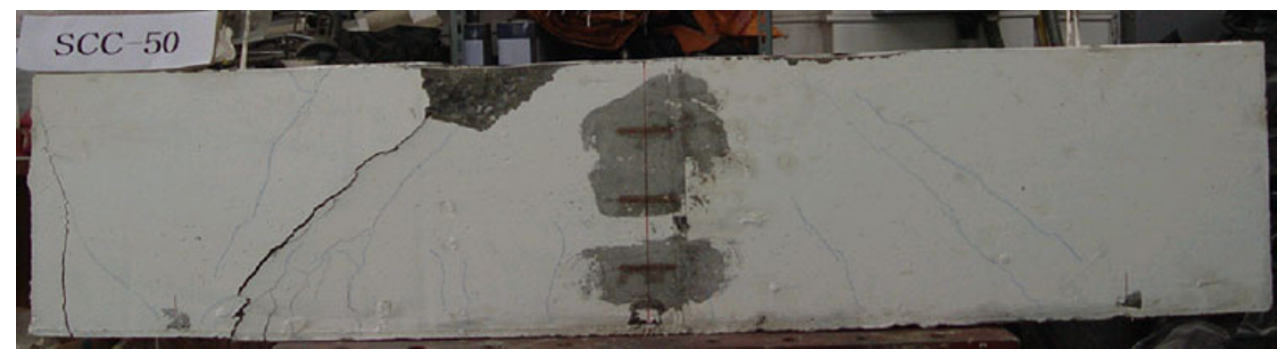

(c) SCC-50 specimen

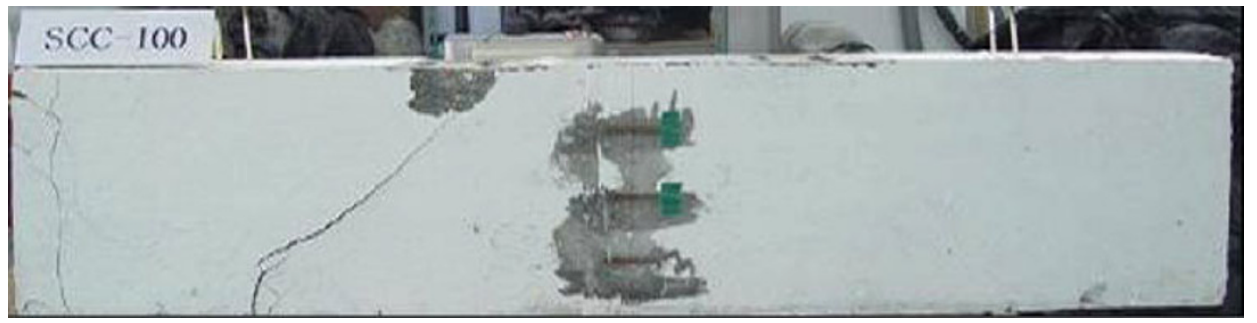

(d) SCC-100 specimen

Fig. 8 Crack patterns and failure modes of the tested deep beams.

to flexural stress at a load of $108 \mathrm{kN}$. As the applied load was increased, the flexural cracks propagated vertically upward to a certain distance from the top of the specimen, but did not penetrate the specimen until meeting the inclined compression strut. With increasing load, diagonal shear cracks formed at both sides of the layers parallel to the inclined compression strut at a load of $245 \mathrm{kN}$. Similar to the NC-100 specimen, sudden failure mode was observed at a load of $715 \mathrm{kN}$.

For all deep beams, flexural cracks in the mid span region within the range of $13-17 \%$ of the ultimate load did not penetrate into the compression zone and stopped at a certain distance from the top of each specimen, since arch action developed at an early load stage in the deep beam, which corresponds to the experimental results by Omeman et al. (2008). For all specimens, diagonal shear cracks within the range of 33-41\% of ultimate load appeared at both sides of the layers parallel to the inclined compression strut and extended simultaneously in both directions downward to the support and upward to load positions of the specimens. Finally, a sudden shear-compression failure was observed with all tested deep beams.

\subsubsection{Load Carrying Capacities and Initial Stiff- ness}

The results from the four-point loading tests on the deep beam made with NC and SCC are summarized in Tables 8 and 9. Table 8 lists the loads at initial flexural cracking and diagonal shear cracking and ultimate loads of all SCC and $\mathrm{NC}$ specimens. In this study, NC-100 and SCC-100 specimens with stirrups spaced at $100 \mathrm{~mm}$ along the span were assumed to be a relatively non-congested shear reinforcement condition. The initial flexural cracking load of the NC-100 and SCC-100 specimens was 88 and $108 \mathrm{kN}$, respectively, while the diagonal shear cracking load of NC-100 and SCC100 specimens was 225 and $245 \mathrm{kN}$, respectively. Diagonal shear cracks were measured within the shear span of the 
Table 8 Load carrying capacities from the four-point loading tests.

\begin{tabular}{|c|c|c|c|c|c|c|c|}
\hline \multirow[t]{2}{*}{ Specimen } & \multicolumn{4}{|c|}{ Cracking loads (kN) } & \multirow{2}{*}{$\begin{array}{l}\text { Ultimate load } \\
\qquad(\mathrm{kN})\end{array}$} & \multirow{2}{*}{$\begin{array}{l}\text { Increase } \\
\text { rate }(\%)\end{array}$} & \multirow{2}{*}{$\begin{array}{l}\text { Failure } \\
\text { mode }\end{array}$} \\
\hline & $\begin{array}{c}\text { Initial } \\
\text { flexural }\end{array}$ & $\begin{array}{l}\text { Increase } \\
\text { rate }(\%)\end{array}$ & $\begin{array}{c}\text { Diagonal } \\
\text { shear }\end{array}$ & $\begin{array}{l}\text { Increase } \\
\text { rate }(\%)\end{array}$ & & & \\
\hline NC-100 & 88 & - & 225 & - & 676 & - & $\mathrm{S}^{*}$ \\
\hline SCC-100 & 108 & 22 & 245 & 9 & 715 & 6 & $\mathrm{~S}^{*}$ \\
\hline NC-50 & 128 & - & 314 & - & 802 & - & $\mathrm{S}^{*}$ \\
\hline SCC-50 & 132 & 4 & 324 & 3 & 796 & -1 & $\mathrm{~S}^{*}$ \\
\hline
\end{tabular}

$S^{*}$ shear-compression failure.

Table 9 The reserve shear strengths and factors.

\begin{tabular}{c|c|c|c|c}
\hline Specimen & $\begin{array}{c}\text { Diagonal shear } \\
\text { strength }(\mathrm{kN})\end{array}$ & $\begin{array}{c}\text { Ultimate shear } \\
\text { strength }(\mathrm{kN})\end{array}$ & $\begin{array}{c}\text { Reserve shear } \\
\text { strength }(\mathrm{kN})\end{array}$ & $\begin{array}{c}\text { Reserve shear } \\
\text { strength factor }\end{array}$ \\
\hline \hline NC-100 & 113 & 338 & 226 & 3.0 \\
\hline SCC-100 & 123 & 358 & 235 & 2.9 \\
\hline NC-50 & 157 & 401 & 244 & 2.6 \\
\hline SCC-50 & 162 & 398 & 236 & 2.5 \\
\hline
\end{tabular}

tested deep beams during the four-point loading tests. 22 and $3 \%$ increases in initial flexural and diagonal shear cracking load in comparison with that of the NCC-100 specimen were observed with the SCC-100 specimen. Percentage ratios of the diagonal shear cracking load to the ultimate load of the NCC-100 and SCC-100 specimens were 33 and $34 \%$ of the ultimate loads, respectively. It can be seen that the SCC specimen with relatively non-congested shear reinforcement showed a slightly higher load carrying capacity than the corresponding NC specimen. NC-50 and SCC-50 specimens with stirrups spaced at $50 \mathrm{~mm}$ along the span were assumed to be a congested reinforcement in shear. The initial flexural cracking load of the NC-50 and SCC-50 specimens was 128 and $132 \mathrm{kN}$, respectively, while the diagonal shear cracking load of the NC-50 and SCC-50 specimens was 314 and $324 \mathrm{kN}$, respectively. Diagonal shear cracks were measured within the shear span of the tested deep beams during the four-point loading tests 4 and $3 \%$ increases in initial flexural and diagonal shear cracking load in comparison with that of the NCC-50 specimen were observed with of the SCC-50 specimen. It can be seen that the SCC specimen with congested shear reinforcement showed a similar load carrying capacity compared to the NC specimen.

The ultimate load capacity of the NC-100 and SCC-100 specimens was 676 and $715 \mathrm{kN}$, respectively. The ultimate load was measured at shear-compression failure of the deep beam under four-point loading tests. A $9 \%$ increase in ultimate load in comparison with that of the NC-100 specimen was observed with the SCC-100 specimen. The ultimate load capacity of the NC-50 and SCC-50 specimens was 802 and $796 \mathrm{kN}$, respectively. The ultimate load was measured at shear-compression failure of the deep beam under four-point loading tests. No significant increase in ultimate load in comparison with that of the NC-50 specimen was observed with the SCC-50 specimen. Percentage ratios of the diagonal shear cracking load to ultimate load of the NCC-50 and SCC50 specimens were 39 and $41 \%$ of the ultimate loads, respectively. This indicates that the SCC specimen has similar shear performance in comparison with the NC specimen even in the case of congested beams with large amount of reinforcements. This corresponds to the findings by Bouzoubaâ and Lachemi (2001) and Lachemi et al. (2005).

As discussed in Sect. 3.2.1, large resisting capacity of the deep beams was observed after the first diagonal shear cracks by the arch action in compressive struts. The reserve shear strength, defined as the difference between the ultimate shear strength and the diagonal shear cracking strength of the deep beams (Yang et al. 2003), of the NC-100 and SCC-100 specimens was 226 and $235 \mathrm{kN}$, respectively, while that of the NC50 and SCC-50 specimens was 244 and $236 \mathrm{kN}$, respectively. As listed in Table 9, the value of the reserve shear strength factor, defined as the ratio of the ultimate shear strength to the diagonal shear cracking strength was defined as reserve shear strength factor used as a criterion to measure the reserve strength (Yang et al. 2003), was 3.0 and 2.9 for the NC-100 and SCC-100 specimens, respectively, while 2.6 and 2.5 for the NC-50 and SCC-50 specimens was shown, respectively. It was found that the SCC specimens showed the similar reserved shear resisting strength in comparison with the $\mathrm{NC}$ specimens even with the two different web reinforcements.

Initial stiffness in the linear elastic stage was calculated from the $p-u$ curves to evaluate the variation of stiffness of the deep beams made with NC and SCC. Figure 9 shows the load versus (mid-span) vertical deflection curves of the deep beam specimens. Initial stiffness of the NC-100 and SCC100 specimens under the four-point loading test was 155 and $156 \mathrm{kN} / \mathrm{mm}$, respectively, while that of the NC-50 and SCC50 specimens was 160 and $156 \mathrm{kN} / \mathrm{mm}$, respectively. The initial stiffness between both the NC-100 and SCC-100 specimens was almost the same, while no significant change 


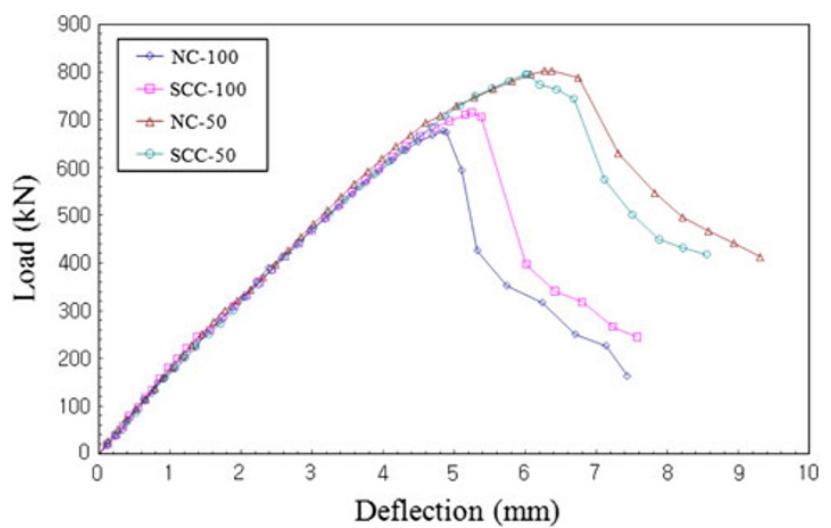

Fig. 9 The load-deflection $(p-u)$ curves of the tested deep beams.

was observed in comparison of the NC-50 specimen with the SCC-50 specimen. It can be seen that all specimens made with SCC and NC exhibited nearly the same initial stiffness, as shown in Fig. 9.

\section{Design Approach}

In this study, the shear strength of deep beams made with $\mathrm{NC}$ and SCC was predicted using the formula in the ACI 318 (1999), Hsu-Mau's explicit method (Hsu 1998; Mau and Hsu 1989) and strut-and-tie model suggested by Uribe and Alcocer (2002) based on ACI 318 Appendix A (2008). In order to evaluate their applicability as a design formula for SCC specimens, experimental results obtained from this study were compared with the prediction results by the aforementioned methods.

\subsection{ACI Design Code}

The design equations in the ACI code (1999) were derived from empirical research of Crist (1971), de Pavia and Siess (1965) and (Stephen and Gilbert 1998). The suggested design equations are applicable to specimens with an effective span-to-depth ratio $l_{n} / d$ less than 5 (ACI 318 1999). The nominal shear strength of a RC section $V_{n}$ for deep beams can be expressed as (ACI 318 1999)

$$
V_{n}=V_{c}+V_{s}
$$

where $V_{c}$ is the shear strength of the concrete for deep beams and $V_{s}$ is the shear strength of reinforcement steel for deep beams. The shear strength of concrete for deep beams is given by (ACI 318 1999)

$$
\begin{aligned}
V_{c}=( & {\left[3.5-2.5 \frac{M_{u}}{V_{u} d}\right] } \\
& {\left.\left[0.15 \sqrt{f_{c}}+120 \rho_{w} \frac{V_{u} d}{7 M_{u}}\right]\right) b_{w} d \leq 0.5 \sqrt{f_{c}} b_{w} d }
\end{aligned}
$$

where $b_{w}$ is web width of the beam $(\mathrm{mm})$, and $d$ is the effective depth (mm), $M_{u}$ and $V_{u}$ are the factored moment $(\mathrm{N} \cdot \mathrm{mm})$ and shear force $(\mathrm{N})$ at the critical section, $f_{c}$ is the compressive strength of concrete $(\mathrm{Pa}), \rho_{w}$ is the longitudinal reinforcement ratio, $A_{s} / b_{w} d$, and $A_{s}$ is the area of longitudinal reinforcement $\left(\mathrm{mm}^{2}\right)$. The first expression in brackets $\left[3.5-2.5 M_{u} / V_{u} d\right]$ in Eq. (2) is the increase in shear strength over the inclined cracking shear and should be more than 2.5 (ACI 318 1999). The second bracketed expression $\left[0.15 \sqrt{f_{c}}+120 \rho_{w} V_{u} d / 7 M_{u}\right]$ exhibits the flexureshear cracking strength for shallow beams (ACI 318 1999). The shear strength of web reinforcement in the deep beams is derived from the shear friction concept, where the sole function of the shear reinforcement is to develop compression force across a slip plane, thereby providing a clamping action (ACI 318 1999). The shear strength of the web reinforcement $V_{s}$ is given by (ACI 318 1999)

$$
V_{s}=f_{s y} d\left[\frac{A_{v}}{s_{v}} \frac{1}{12}\left(1+\frac{l_{n}}{d}\right)+\frac{A_{v h}}{s_{h}} \frac{1}{12}\left(11-\frac{l_{n}}{d}\right)\right]
$$

where $f_{s y}$ is the yield strength of the web reinforcement $(\mathrm{Pa})$, $A_{v}$ and $A_{v h}$ are the vertical and horizontal web reinforcement $\left(\mathrm{mm}^{2}\right)$, respectively, $s_{v}$ and $s_{h}$ are the spacing of the vertical and horizontal web reinforcement $(\mathrm{mm})$.

\subsection{Hsu-Mau's Explicit Method}

A theoretical model was developed by Mau and Hsu (1987) to predict the shear strength of a deep beam with web reinforcement by introducing an effective transverse compression in the web of the deep beam. When a concentrated load is applied to the top surface of a deep beam, a shear element between one of the load points and the nearest support from the load point could be subjected to a shear stress and a vertical or transverse compressive stress (Hsu 1998). In their theory, the transverse compressive stress is affected by not only shear force but also the shear-span-ratio (Mau and Hsu 1987; Hsu 1998). In order to simplify the theoretical model developed by Mau and Hsu (1987), the following simple equation for the shear strength of a deep beam $V_{n}$ was suggested by Mau and Hsu (1989):

$$
V_{n}=v_{u} b d_{v} \leq 0.3 b d_{v}
$$

where $v_{u}$ is the ultimate shear stresses of a RC section for a deep beam, $b$ is the width of the deep beam, and $d_{v}$ is the distance between the centroid of the top and bottom stringers. The ultimate shear stresses for the deep beam $v_{u}$ is given by Mau and Hsu (1989)

$$
\begin{aligned}
v_{u}= & \frac{1}{2} f_{c}^{\prime}\left[K\left(\omega_{l}+0.03\right)\right. \\
& \left.+\sqrt{K^{2}\left(\omega_{l}+0.03\right)^{2}+4\left(\omega_{l}+0.03\right)\left(\omega_{t}+0.03\right)}\right]
\end{aligned}
$$

where $f_{c}^{\prime}$ is the maximum compressive strength of concrete, $\omega_{l}=\rho_{l} f_{l y} / f_{c}^{\prime} \leq 0.26$ is the reinforcement index in the longitudinal (horizontal) direction, $\omega_{t}=\rho_{t} f_{t y} \leq 0.12$ is the reinforcement index in the transverse (vertical) direction, $\rho_{l}$ and $\rho_{l}$ are the steel reinforcement ratio in the horizontal and 


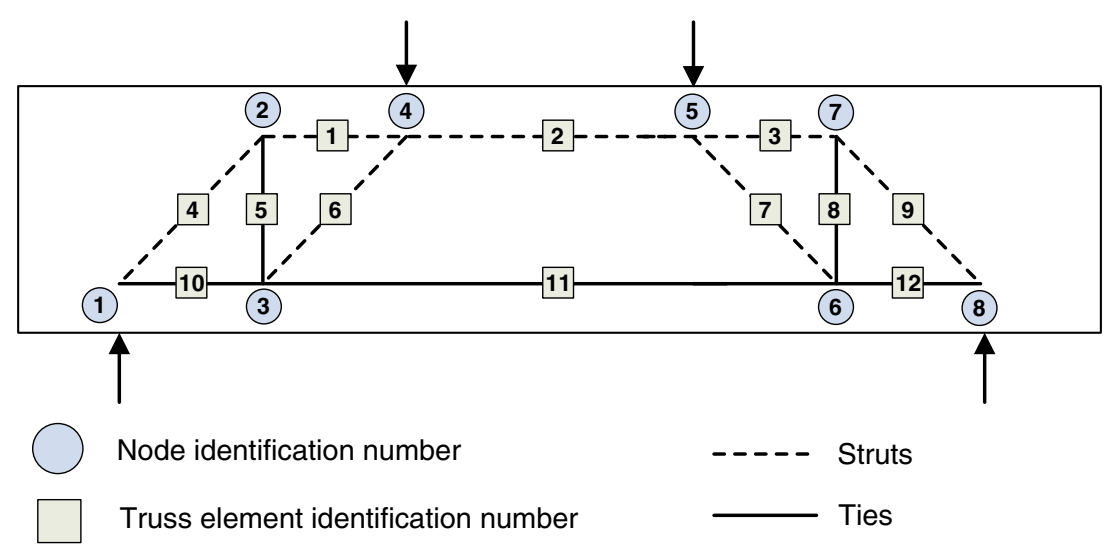

Fig. 10 Strut-and-tie model for the deep beam.

Table 10 The comparison between prediction results and experimental data.

\begin{tabular}{c|c|c|c|c|c|c|c}
\hline Specimen & Experimental & \multicolumn{3}{|c|}{ Prediction results (kN) } & \multicolumn{3}{|c}{ Comparison (ratio) } \\
\cline { 3 - 8 } & results (kN) (1) & $\begin{array}{c}\text { ACI 318-99 } \\
(2)\end{array}$ & $\begin{array}{c}\text { Hsu-Mau's } \\
\text { method (3) }\end{array}$ & $\begin{array}{c}\text { Strut-and-tie } \\
\text { model (4) }\end{array}$ & $(1) /(2)$ & $(1) /(3)$ & $(1) /(4)$ \\
\hline \hline NC-100 & 338 & 126 & 177 & 113 & 2.7 & 1.9 & 3.0 \\
\hline SCC-100 & 358 & 126 & 167 & 113 & 2.8 & 2.1 & 3.2 \\
\hline NC-50 & 401 & 159 & 177 & 226 & 2.5 & 2.3 & 1.8 \\
\hline SCC-50 & 398 & 159 & 167 & 226 & 2.5 & 2.4 & 1.8 \\
\hline
\end{tabular}

vertical direction, respectively, and $f_{l y}$ and $f_{t y}$ are average steel stresses in the horizontal and vertical direction, respectively. In Eq. (5), $K$ is a function of the shear span ratio and is defined as (Hsu 1998)

$$
K=\left[\begin{array}{cc}
2 d_{v} / h & 0<a / h<0.5 \\
\frac{d_{v}}{h}\left[\frac{4}{3}\left(\frac{h}{a}-\frac{1}{2}\right)\right] & 0.5<a / h<2 \\
0 & a / h>2
\end{array}\right.
$$

where $h$ is the total depth of the beam and $a$ is the shear span of the beam.

\subsection{Strut and Tie Model}

The strut-and-tie methodology with the use of truss models is known to be suitable for the shear design and analysis of the discontinuity region of the structural members such as corbels, pier caps and deep beams (Bakir and Boduroĝlu 2005). In general, strut-and-tie model recommended by Uribe and Alcocer (2002) based on the ACI 318 Appendix A (2002) can provide a framework to understand the flow of stress and forces and assess the resisting mechanism of a deep beam. In this study, the Uribe and Alcocer's strut-and-tie model (2002) based on ACI 318-08 Appendix A (2008) was used to estimate the shear strength of the deep beams made with NC and SCC. The effective strengths and factors for strut, tie and nodal zone in the strut-and-tie model are defined as recommended by ACI 318-08 Appendix A (2008).

$$
\begin{aligned}
& F_{n s}=f_{c e} A_{c s} \\
& F_{n t}=f_{y} A_{t s}
\end{aligned}
$$

$$
\begin{aligned}
& F_{n n}=f_{c e} A_{n z} \\
& f_{c e}=0.85 \beta_{2} f_{c}
\end{aligned}
$$

where $F_{n s}$ is the nominal compressive strength of the concrete in a strut, $F_{n t}$ is the nominal strength of a tie, $F_{n n}$ is the nominal compressive strength of a nodal zone, $A_{c s}$ is the smallest effective cross-sectional area of a strut, $A_{t s}$ is the area of nonprestressed reinforcement, $A_{n z}$ is the area of the face of the nodal zone, $f_{c e}$ is the effective compressive strength, $\beta_{2}$ is the factor account for the effect cracking and confining reinforcement on the effective compressive strength of a strut, $\beta_{s}$ (ACI 318 2008). The discontinuity regions of deep beam were modeled by using hypothetical trusses consisting of concrete struts in compression area, steel ties in tension region and nodes at joints, as illustrated in Fig. 10.

\subsection{Comparative Study}

The shear strengths of deep beams made with $\mathrm{NC}$ and SCC were calculated in accordance with ACI 318 (1999) and Hsu-Mau's explicit method (Mau and Hsu 1989; Hsu 1998). The calculated theoretical results were compared with the present experimental data. In this study, the experimental data for the shear strength of deep beam were given by calculating the shear force within shear span from load position to near support. As listed in Table 10, this comparative approach revealed that the experimental results were approximately $2.5-2.8$ times greater than the theoretical results predicted using ACI 318 (1999). The shear strengths of the NC-100 and SCC-100 specimens were approximately 2.7 and 2.8 times greater than the theoretical values, 
respectively, while the strengths of both the $\mathrm{NC}-50$ and SCC-50 specimens were approximately 2.5 times greater than the theoretical values. Prediction results based on ACI 318 (1999) were found to be very conservative.

The comparative approach showed that the experimental results were approximately 1.9-2.4 times greater than the theoretical results calculated using Hsu-Mau's explicit method (Hsu 1998; Mau and Hsu 1989). The shear strengths of the NC-100 and SCC-100 specimens were approximately 1.9 and 2.1 times greater than the theoretical results, respectively, while both the NC-50 and SCC-50 specimens were approximately 2.3 and 2.4 times greater than the theoretical results, respectively. It was found that the prediction results by using the formula of Hsu-Mau's explicit method (Hsu 1998; Mau and Hsu 1989) were very conservative.

In addition, the comparative study exhibited that the experimental results were approximately 1.8-3.2 times greater than the theoretical results predicted by Uribe and Alcocer (2002) based on the ACI 318 Appendix A (2002). The shear strengths of the NC-100 and SCC-100 specimens were approximately 3.0 and 3.2 times greater than the theoretical results, respectively, while both the NC-50 and SCC50 specimens were approximately 1.8 times greater than the theoretical results.

The prediction results by Uribe and Alcocer (2002)'s strutand-tie model for the NC- and SCC-100 specimens with relatively non-congested web reinforcements were shown to be the lowest among the three theoretical approaches, while the lowest predicted shear strength was obtained when using the ACI 318 formula (1999) for the NC- and SCC-50 specimens with congested web reinforcements.

\section{Conclusions}

A series of experimental tests were carried out to evaluate fresh properties of SCC and to investigate the shear behavior and performance of deep beams made with SCC during fourpoint loading tests. Fresh properties of the NC and SCC were evaluated based on the slump, slump flow, and V-funnel and U-box tests. The workability and compacting ability were also observed based on casting time and number of surface cavities. Shear behavior and performance of RC deep beams having two different reinforcements in shear were systematically investigated in terms of crack pattern, failure mode, and load-deflection response. In addition, comparisons between the present experimental data and theoretical results in accordance with ACI 318 (1999), HsuMau's explicit method (Hsu 1998; Mau and Hsu 1989) and strut-and-tie model suggested by Uribe and Alcocer (2002) based on ACI 318 (2008) were made to evaluate the applicability of existing theoretical methods as design formula for the deep beam made with SCC. The findings of the present study can be summarized as follows.

1. It was shown from the slump flow, V-funnel and U-box tests that the fresh properties of the SCC satisfied the requirements in accordance with 1st class criteria of JSCE (2005).

2. The casting time of the SCC specimens was significantly shorter than that of the NC-specimens in the case of both relatively non-congested and congested shear reinforcement conditions. It was concluded that the influence of the concrete type (e.g., NC and SCC mixes) on the casting time was shown to be very significant.

3. For all specimens, diagonal shear cracks appeared at both sides of the layers parallel to the inclined compression strut and extended simultaneously in both directions downward to the support and upward to load positions of the specimens. Finally, sudden shear-compression failure was observed with all tested deep beams.

4. The SCC specimens with the relatively non-congested web reinforcement showed a slightly higher load carrying capacity in terms of diagonal shear cracking and ultimate loads compared to the NC specimens. However, SCC specimens with the congested web reinforcement exhibited a similar load carrying capacity in terms of ultimate load compared to the NC specimen.

5. The SCC specimens showed similar reserve shear strength factor in comparison with the NC specimens even with the two different web reinforcements. It was found that the SCC specimens showed similar reserved shear resisting strength by the arch action compared to NC specimens.

6. It was seen that all specimens made with SCC and NC exhibited nearly the same initial stiffness.

7. The predicted shear strengths by Uribe and Alcocer's (2002) strut-and-tie model for the NC- and SCC-100 specimens with relatively non-congested web reinforcements were shown to be the lowest among the three theoretical approaches, whereas the prediction results using the ACI 318 formula (1999) for the NC- and SCC50 specimens with congested web reinforcements were shown to be the lowest.

\section{Acknowledgments}

The authors would like to sincerely thank T.H. An, Mr. J.N. Lee, Mr. J.H. Eom, Mr. J.H. Kim, Mr. M.S. Park, Mr. B.K. Choi, and Mr. N.W. Yang at Semyung University, Korea for preparing the specimens and helping to conduct the relevant tests. We also thank the cooperation of Mr. R. Tawie, S.K. $\mathrm{Ha}$ and Sam $\mathrm{Na}$ at the Korea Advanced Institute of Science and Technology (KAIST). This research was funded by the Ministry of Construction and Transportation of Korea through "Center for Concrete Corea".

\section{Open Access}

This article is distributed under the terms of the Creative Commons Attribution License which permits any use, distribution, and reproduction in any medium, provided the original author(s) and the source are credited. 


\section{References}

ACI Committee 318. (1999). Building code requirements for reinforced concrete (ACI 318-89) and commentary-ACI 318R-89. Farmington Hills: American Concrete Institute.

ACI Committee 318. (2008). Building code requirements for reinforced concrete and commentary (ACI 318M-08), American Concrete Institute.

ASTM. (2003). Standard test method for slump of hydrauliccement concrete. C143 M-03, West Conshohocken, Pennsylvania.

ASTM. (2005). Standard test method for compressive strength of cylindrical concrete specimens. C39-05, West Conshohocken, Pennsylvania.

ASTM. (2007). Standard practice for making and curing concrete test specimens in the laboratory. C192-07, West Conshohocken, Pennsylvania.

Bakir, P. G., \& Boduroĝlu, H. M. (2005). Mechanical behavior and non-linear analysis of short beams using softened truss and direct strut and tie models. Engineering Structures, 27, 639-651.

Bouzoubaâ, N., \& Lachemi, M. (2001). Self-compacting concrete incorporating high volumes of class F fly ash: Preliminary results. Cement and Concrete Research, 31, 413420.

Broomfield, J. (2003). The identification and assessment of defects, damage and decay. In S. MacDonald (Ed.), Concrete: Building pathology. Oxon: Blackwell.

Choi, Y. W., Cho, S. K., Choi, W., Kim, K. H., \& An, S. I. (2003). Properties of medium strength self-compacting concrete with simple mix design method. Proceedings of the Korea Concrete Institute, 15, 83-88.

Choi, Y. W., Jung, M. Y., Chung, J. S., Moon, D. J., \& An, S. I. (2002). Optimum mixture proportion of self-compacting concrete considering packing factor of aggregate and fine aggregate volume ratio. Proceedings of the Korea Concrete Institute, 14, 549-554.

Choi, Y. W., Kim, Y. J., \& Kang, H. J. (2008). A study on the flowability properties of the high flowing self-compacting concrete for members of bridge precast. Korea Society of Civil Engineers, 28, 155-163.

Choi, Y. W., Kim, Y. J., Shin, H. C., \& Moon, H. Y. (2006). An experimental research on the fluidity and mechanical properties of high-strength lightweight self-compacting concrete. Cement and Concrete Research, 36, 1595-1602.

Choulli, Y., Marí, A. R., \& Cladera, A. (2008). Shear behavior of full-scale prestressed I-beams made with self compacting concrete. Materials and Structures, 41, 131-141.

Crist, R. A. (1971). Static and dynamic shear behavior of uniformly reinforced concrete deep beams. Report No. AFWL-TR-71-74, University of New Mexico (CERF), Kirkland Air Force Base, Mexico, November, 1971.

de Pavia, H. A. R., \& Siess, C. P. (1965). Strength and behavior of deep beams in shear. ASCE Proceedings, 91, 19-41.
Domone, P. L. (2006). Self-compacting concrete: An analysis of 11 years of case studies. Cement and Concrete Composites, $28,197-208$.

Hassan, A. A. A., Hossain, K. M. A., \& Lachemi, M. (2008). Behavior of full-scale self-consolidating concrete beams in shear. Cement and Concrete Composites, 30, 588-596.

Hassan, A. A. A., Hossain, K. M. A., \& Lachemi, M. (2010). Structural assessment of corroded self-consolidating concrete beams. Engineering Structures, 32, 874-885.

Hsu, T. T. C. (1998). Unified approach to shear analysis and design. Cement and Concrete Composites, 20, 419-435.

Japan Society of Civil Engineering (2005). Guide to construction of high flowing concrete, Gihoudou Pub, Tokyo.

Lachemi, M., Hassain, K. M. A., Lambros, V., Nkinamubanzi, P. C., \& Bouzoubaâ, N. (2005). Self-compacting concrete incorporating new viscosity modifying admixtures. Cement and Concrete Research, 24, 917-926.

Londhe, R. S. (2011). Shear strength analysis and prediction of reinforced concrete transfer beams in high-rise buildings. Structural Engineering and Mechanics, 37(1), 39-59.

MacGregor, J., \& Wight, J. K. (2006). Reinforced concrete mechanics and design: Fourth edition in SI units. Upper Saddle River, NJ: Prentice Hall.

Mau, S. T., \& Hsu, T. T. C. (1987). Shear strength prediction for deep beams with web reinforcement. ACI Structural Journal, 84, 513-523.

Mau, S. T., \& Hsu, T. T. C. (1989). Formula for the shear design of deep beam. Structural Journal of the American Concrete Institute, 86, 516-523.

Okamura, H. (1999). Self-compacting high performance concrete. Tokyo: Social System Institute.

Okamura, H., Maekawa, K., \& Ozawa, K. (1998). High performance concrete. Tokyo: Gihoudou Pub.

Omeman, Z., Nehdi, M., \& El-Chabib, H. (2008). Experimental study on shear behavior of carbon-fiber-reinforced polymer reinforced concrete short beams without web reinforcement. Canadian Journal of Civil Engineering, 35(1), 1-10.

Shah, D. L., \& Modhera, C. D. (2010). Evaluation of shear strength of self compacting concrete deep beam. International Journal of Advanced Engineering Technology, 1, 292-305.

Stephen, J. F., \& Gilbert, R. I. (1998). Experimental studies on high-strength concrete deep beams. ACI Structural Journal, 95, 382-390.

Su, N., Hsu, K. C., \& Chai, H. W. (2001). A simple mix design method for self-compacting concrete. Cement and Concrete Research, 31, 1799-1807.

Uribe, C. S., \& Alcocer, S. M. (2002). SP-208 Example 1a: Deep beam design in accordance with ACI 318-2002. American Concrete Institute, 65-81.

Yang, K. H., Chung, H. S., Lee, E. T., \& Eun, H. C. (2003). Shear characteristics of high-strength concrete deep beams without shear reinforcements. Engineering Structures, 25, $1343-1352$. 